\title{
Responses of the Bush Warbler Cettia diphone to artificial eggs of Cuculus cuckoos in Japan
}

\author{
HIROYOSHI HIGUCHI* \\ Laboratory of Forest Zoology, Faculty of Agriculture, The University of Tokyo, \\ Tokyo 113, fapan and Museum of Zoology, The University of Michigan, Ann \\ Arbor, Michigan 48109, U.S.A.
}

Accepted 8 August 1987

\begin{abstract}
Artificial eggs of six different colours and control eggs of Bush Warblers Cettia diphone were introduced into nests of Bush Warblers, a host of both Little and Himalayan Cuckoos Cuculus poliocephalus and $C$. saturatus in Japan. All control (chocolate-brown) and artificial red eggs were accepted; all grey and all white eggs were rejected. The rejection rates of orange, pink and orange spots on grey eggs were $8 \%, 36 \%$ and $55 \%$, respectively. Bush Warblers are more likely to reject eggs the more dissimilar they are from their own. The results strengthen the possibility that the chocolate-brown eggs of Little and Himalayan Cuckoos may have evolved through the discriminative ability of Bush Warblers and their intolerance towards dissimilar eggs.
\end{abstract}

In Honshu (the largest island of Japan) the Little Cuckoo Cuculus poliocephalus parasitizes mainly the Bush Warbler Cettia diphone and lays chocolate-brown eggs, that resemble those of this host in colour (Kobayashi \& Ishizawa 1940, Kiyosu 1965, Higuchi 1978). The sympatric Himalayan Cuckoo $C$. saturatus mainly parasitizes the Crowned Willow Warbler Phylloscopus occipitalis and lays whitish eggs with brownish spots, its are not so similar in colour to those of Crowned Willow Warblers (Kobayashi \& Ishizawa 1940, Kiyosu 1965, Higushi 1978). In Hokkaido (the second largest northern island), few Little Cuckoos breed. Instead, Himalayan Cuckoos parasitize Bush Warblers and lay chocolate-brown eggs which are very similar to those of Bush Warblers (Higuchi \& Sato 1984, Higuchi 1986). The chocolate-brown eggs of Little and Himalayan Cuckoos may have evolved through the discriminative ability of Bush Warblers.

Many experiments on egg introduction into the nests of host species have been conducted (e.g., Swynnerton 1918, Rensch 1924, Ali 1931, Victoria 1972, Alvarez et al. 1976, Nibe 1979, von Haartman 1981, Rothstein 1975, 1982, Mason 1986). However, quantitative data are scant, particularly on the hosts of Cuculus cuckoos. The present paper provides the results of the introduction of artificial eggs of several different colours into the nests of Bush Warblers. It is shown that Bush Warblers tend to reject dissimilar eggs more often than similar ones.

\section{Study area and methods}

The study was carried out from April to July in $1982-85$ on Miyake island ( $\left.34^{\circ} 30^{\prime} \mathrm{N}, 139^{\circ} 30^{\prime} \mathrm{E}\right)$ of the Izu

* Present Address: Research Center, Wild Bird Society of Japan, Higashi 2-24-5, Shibuya-ku, Tokyo 150, Japan. 
Table 1. Munsell code for the colours of artificial and control eggs

\begin{tabular}{|c|c|c|c|}
\hline \multirow[b]{2}{*}{ Name of colour } & \multicolumn{3}{|c|}{ Munsell code } \\
\hline & Hue & Value & Chroma \\
\hline Red & $7 \cdot 0 \mathrm{R}$ & 4.5 & $14 \cdot 0$ \\
\hline Orange & $9 \cdot 0 \mathrm{R}$ & $5 \cdot 5$ & $14 \cdot 0$ \\
\hline Pink & $6.5 \mathrm{RP}$ & $7 \cdot 0$ & $10 \cdot 5$ \\
\hline Grey & $6.5 \mathrm{~PB}$ & $4 \cdot 0$ & $4 \cdot 0$ \\
\hline White & $N($ neutral) & $9 \cdot 5$ & 0 \\
\hline $\begin{array}{l}\text { Chocolate-brown } \\
\text { (control) }\end{array}$ & $7 \cdot 5 \mathrm{R}$ & $3 \cdot 0-4 \cdot 0$ & $6 \cdot 0-7 \cdot 5$ \\
\hline
\end{tabular}

Islands, central Japan. This area was selected because of the high density of Bush Warblers but low density of nest-predators such as snakes. The environment has been described in detail in Higuchi (1975). Although four cuckoo species breed in Honshu, only Little Cuckoos breed on Miyake (Higuchi 1973).

I searched for nests of Bush Warblers in the birds' preferred habitat: secondary forests with bamboo bush. Experiments were performed at nests where incubation had proceeded for four days or less. Many nests of that stage were found and the early incubation stage is when the cuckoos usually deposit their eggs (Higuchi, unpubl.). One egg model was added to each of 47 nests, and two to four egg models were introduced into each of 55 other nests. In the latter cases, one egg model was added on the first day and was replaced by another artificial egg on the next day. Hence, only one egg was introduced into a nest at a time. One real egg was removed from each Bush Warbler nest when the first artificial egg was added. No birds were tested more than once with the same egg type. Only female Bush Warblers incubate. Hence, responses to artifical eggs indicate female behaviour.

Plastic eggs were used in the experiments. Six colour models were prepared by painting with pigment ink or latex house paint: red $(R)$, orange $(O)$, pink $(P)$, grey spotted with orange $(G O)$, grey $(G)$, and white (W). These names of colour were chosen for simplicity. It may be better to call the orange 'reddish orange', the pink 'light purplish red', and the grey 'bluish grey'. The five colours used in painting were quantified by the Munsell code (Table 1). The spots on a GO egg covered $40-50 \%$ of the egg's surface area. For controls, real eggs of Bush Warblers were also used. The mean size and weight of artificial eggs were $19.2 \times 12.8 \mathrm{~mm}$ and $1.2 \mathrm{~g}(n=15)$, and the mean size and weight of Bush Warbler eggs were $18.3 \times 13.6 \mathrm{~mm}$ and $1.8 \mathrm{~g}(n=16)$.

The extent of difference of the five colours from the control egg was examined using the Munsell code. In the Munsell colour system, each colour recognized occupies a particular site in the three dimensions of Hue, Value, and Chroma (Munsell 1929). The Munsell scale is subjective, not based on physical measurements, but for comparing the colours of the test egg the scale is thought to be reasonable. The chocolate-brown (control), red, and orange colours belong to the Red zone of Hue, and are close to each other. The difference in the Munsell code between control and red is smaller $(0.5$ for Hue and $0.5-1.5$ for Value) than the difference between control and orange ( 1.5 for Hue and 1.5-2.5 for Value). Pink belongs to the RP zone of Hue and is a little farther from control than red and orange, but is closer to control than grey and white. Grey and white are far away from control, and it is hard to see which is the closer. It is therefore apparent that the difference in colour from the Bush Warbler egg increases in the order $R, O, P, G$ and $W$.

To test the effect of the plastic eggs on the ability of Bush Warblers to eject eggs, I added four whitish eggs of Great Tits Parus major and three bluish eggs of Japanese White-eyes Zosterops japonica to the nests of Bush Warblers. The tit eggs were smaller (mean size: $16.9 \times 13.4 \mathrm{~mm}$ ) than those of Bush Warblers, and the white-eye eggs were almost the same size $(18.0 \times 13.5 \mathrm{~mm})$ as those of Bush Warblers.

Each nest was checked between 24 and 30 hours after the introduction of the eggs. The responses of Bush Warblers were classified as: (1) acceptance, (2) desertion of the entire clutch, (3) ejection of the introduced egg. However, since ejection was rare, ejection and desertion were grouped together into rejection in order to use Fisher's exact probability test (two-tailed). The nest was examined at least three times to determine if it was deserted or not. 
Table 2. Acceptance by Bush Warblers of orange, pink, and grey spotted with orange eggs in relation to the sequence of test

\begin{tabular}{|c|c|c|c|c|c|c|}
\hline \multirow[b]{2}{*}{ Sequence of test } & \multicolumn{2}{|c|}{ Orange } & \multicolumn{2}{|c|}{ Pink } & \multicolumn{2}{|c|}{ Grey with orange spots } \\
\hline & $\begin{array}{c}\text { Accepted } \\
n\end{array}$ & $\begin{array}{c}\text { Rejected } \\
n\end{array}$ & $\begin{array}{c}\text { Accepted } \\
n\end{array}$ & $\begin{array}{c}\text { Rejected } \\
n\end{array}$ & $\begin{array}{c}\text { Accepted } \\
n\end{array}$ & $\begin{array}{c}\text { Rejected } \\
n\end{array}$ \\
\hline First & 20 & 2 & 12 & 7 & 5 & 8 \\
\hline Second & 13 & 1 & 14 & 8 & 4 & 3 \\
\hline Third + Fourth & 2 & 0 & 8 & 4 & 4 & 5 \\
\hline
\end{tabular}

- These were grouped together because there were few fourth tests $(n=6)$.

\section{Results and discussion}

\section{The influence of the order of introduction}

All 16 control eggs and all 32 artificial red eggs were accepted regardless of the sequence. Conversely, all 14 grey and 17 white eggs were rejected regardless of the sequence. The response to the other three egg models varied from test to test. To determine whether the sequence of test was associated with response, I examined the likelihood of rejection in first, second, and subsequent tests (Table 2). No significant differences were found in any combinations of sequence for each colour $(P>0.05)$.

A second possible effect upon acceptance of an egg is the colour of the previous egg-did a Bush Warbler tend to reject an egg that followed another of a different colour? The rejection rate of $P$ was not significantly different when $G O$ was introduced on the day before $P$ was added nor when either $C, R$, or $O$ with high acceptance rates (no significant difference among these, see below) was introduced on the day before $(P=0.804)$. Similarly, the rejection rate of GO was not significantly different when either $\mathrm{P}, \mathrm{C}, \mathrm{R}$, or $\mathrm{O}$ was introduced on the day before $(P=1.000)$. I conclude that the order of egg introduction does not affect rejection rates in the Bush Warbler.

\section{Tolerance toward different egg models}

The tolerance of each individual toward different egg colours could be seen from consecutive introductions (one test per day). For example, a female accepted an $O$ egg but later rejected $P$ and $W$ eggs; another female accepted $O$ and $P$, and then rejected $G O$; another rejected $O$, accepted $R$, then deserted in response to $G$. Of the three egg models ( $O, P$ and $G O)$ that were rejected, $O$ tended to be tolerated more than $P$, which tended to be tolerated more than GO.

The rejection rates of the seven types of eggs are shown in Table 3. The rejection rates (\% desertion and ejection) ranged from $0 \%$ in $\mathrm{C}$ and $\mathrm{R}, 8 \%$ in $\mathrm{O}, 36 \%$ in $\mathrm{P}$, $55 \%$ in GO, to $100 \%$ in $\mathrm{G}$ and $\mathrm{W}$. There were no significant differences among responses to $C, R$ and $O$, between $P$ and $G O$, or between $G$ and $W(P>0.05$, pairwise Fisher's exact probability test). Since the difference in colour from the Bush Warbler's egg increases in the order $R, O, P, G$ and $W$, it is apparent that Bush Warblers are more likely to reject the eggs that are least like their own. It is remarkable that the rejection rate of $G O$ was much smaller than that of $G$, and presumably the orange spots of GO contributed greatly to its acceptance. 
Table 3. The responses of Bush Warblers to eggs of different colours.

\begin{tabular}{|c|c|c|c|c|c|c|c|c|c|c|c|c|}
\hline \multirow[b]{2}{*}{ Eggs } & \multirow{2}{*}{$\begin{array}{l}\text { Code } \\
\text { letters }\end{array}$} & \multirow[b]{2}{*}{$n$} & \multirow{2}{*}{$\begin{array}{c}\text { Acceptance } \\
0 \\
0\end{array}$} & \multirow{2}{*}{$\begin{array}{c}\text { Desertion } \\
0_{0}\end{array}$} & \multirow{2}{*}{$\begin{array}{c}\text { Ejection } \\
0 \\
0\end{array}$} & \multicolumn{7}{|c|}{$\begin{array}{c}\text { Significance levels of differ- } \\
\text { ence } \dagger\end{array}$} \\
\hline & & & & & & w & $\mathbf{G}$ & GO & $P$ & 0 & $\mathbf{R}$ & C \\
\hline $\begin{array}{l}\text { Control } \\
\text { (Bush Warbler) }\end{array}$ & $\mathrm{C}$ & 16 & 100 & 0 & 0 & ** & ** & ** & * & n.s. & n.s. & \\
\hline Red & $\mathbf{R}$ & 32 & 100 & 0 & $\mathbf{0}$ & $* *$ & $* *$ & $* *$ & ** & n.s. & & \\
\hline Orange & $\mathrm{O}$ & 38 & 92 & 0 & 8 & ** & ** & $* *$ & $*$ & & & \\
\hline Pink & $\mathbf{P}$ & 53 & 64 & 27 & 9 & $* *$ & ** & n.s. & & & & \\
\hline Grey with orange spots & GO & 29 & 45 & 52 & 3 & $* *$ & $*$ & & & & & \\
\hline Grey & $\mathrm{G}$ & 14 & 0 & 100 & 0 & n.s. & & & & & & \\
\hline White & $\mathbf{W}$ & 17 & 0 & 100 & 0 & & & & & & & \\
\hline
\end{tabular}

† Fisher's exact probability test (two-tailed). ${ }^{*} P<0 \cdot 01,{ }^{* *} P<0 \cdot 001$, n.s. not significant $P>0 \cdot 05$.

These results strengthen the possibility that the chocolate-brown eggs of Little and Himalayan Cuckoos evolved in response to the ability of Bush Warblers to discriminate among eggs in their own nests and to behave in an appropriate intolerant manner to eggs unlike their own. Another explanation instead of mimicry of the host eggs is that cuckoos might have evolved the same egg colour because, by laying in the same nest as the hosts, they are subject to the same selection pressures for crypsis related to nest structure and predation (Harrison 1968, von Haartman 1981, Mason \& Rothstein 1987). Bush Warblers build nests with a side entrance in dense bamboo thickets. The same type of nest is built by Ijima's Willow Warblers Phylloscopus ijimae in similar habitat on Miyake Island, but that species lays plain white eggs. Therefore, it seems unlikely that the domed nest of Bush Warblers has influenced the similarity in egg colour of the cuckoos and Bush Warblers.

\section{Nest desertion and egg ejection}

Bush Warblers often rejected artificial eggs by desertion rather than ejection. This differs from many other host species (e.g., Victoria (1972) for Village Weavers Ploceus cucullatus, Alvarez et al. (1976) for Magpies Pica pica, Nibe (1979) for Bullheaded Shrikes Lanius bucephalus, von Haartman (1981) for Redstarts Phoenicurus phoenicurus, Rothstein $(1975,1982)$ for several North American passerines, Mason (1986) for some South American passerines). Twenty nine (76\%) of the 38 rejections by Bush Warblers were in the form of desertion.

In all seven introductions of eggs of Great Tits and White-eyes, the nest was deserted by Bush Warblers, and no eggs were ejected. It is therefore unlikely that the frequent desertion of artificial plastic eggs was due to the inability of Bush Warblers to hold such eggs in their bills. Moreover, it is presumably not difficult for Bush Warblers to remove eggs from the side entrance of the nest, which is only $1.5-2.0 \mathrm{~cm}$ above the nest floor.

Nest desertion may be a more reliable way for the host to reject foreign eggs than ejection, which may result in the removal of its own eggs. However, desertion is more costly than ejection (Rothstein (1975) has discussed further disadvantages of desertion). If Bush Warblers both desert and eject, it would be reasonable to expect that more dissimilar eggs are ejected and similar eggs are deserted with the nest. However, the reverse is shown in Table 3. It is not known why Bush Warblers do so and why they desert so often. 
I thank Masami Hasegawa and Masahiko Yamamoto for field assistance, and Robert B. Payne, Stephen I. Rothstein, Paul Mason, and Steven M. Goodman for commenting on the draft. This work was supported in part by a grant-in-aid for the Special Research Project on the Biological Aspects of Optimal Strategy and Social Structure from the Japan Ministry of Education, Science and Culture (Nos. 59215002 and 60107002).

\section{References}

AI.I, S.A. 1931. The origin of mimicry in cuckoo eggs. J. Bombay Nat. Hist. Soc. 34: 1067 1070.

Alvarez, F., De Reyna, L.A. \& Segura, M. 1976. Experimental brood parasitism of the Magpie (Pica pica). Anim. Behav. 24: 907-916.

Harrison, C.J.O. 1968. Egg mimicry in British Cuckoos. Bird Study 15: 22-28.

Haartman, L. von 1981. Co-evolution of the Cuckoo Cuculus canorus and a regular Cuckoo host. (Ornis Fennica 58: 1-10.

Higuchi, H. 1973. Birds of the Izu Islands. (1) Distribution and habitat of the breeding land and freshwater birds. Tori 22: 14-24. (In Japanese with English summary.)

Higuchi, H. 1975. Comparative study on the breeding of mainland and island subspecies of the Varied Tit, Parus varius. Tori $25: 10-20$.

Higuchi, H. 1978. Ecology and Evolution of Birds. Tokyo: Shisakusha. (In Japanese.)

HıguchI, H. 1986. Adaptations for brood parasitism in cuckoos. In Yamagishi, S. (ed.), Breeding Strategies in Birds, Volume 2: 1-31. Tokyo: Tokaidaigaku Shuppan. (In Japanese.)

Higuchi, H. \& Sato, S. 1984. An example of character release in host selection and egg colour of cuckoos Cuculus spp. in Japan. Ibis 126: 398-404.

Kobayashi, K. \& Ishizawa, T. 1940. The eggs of Japanese Birds, II. Kobe: published by the authors.

KiYosv, Y. 1965. The Birds of Japan, II. Tokyo: Kodansha. (In Japanese.)

Mason, P. 1986. Brood parasitism in a host generalist, the Shiny Cowbird: I. The quality of different species as hosts. Auk 103: 52-60.

Mason, P. \& Rothstein, S.I. 1987. Crypsis versus mimicry and the color of Shiny Cowbird eggs. Am. Nat. 130: 161-167.

Munsel.t, A.H. 1929. Munsell Book of Color. Baltimore: Munsell Color Company.

Nibe, T. 1979. The Ecology of Wild Birds, I. Tokyo: Taishukan. (In Japanese.)

Rensch, B. 1924. Zur Entstehung der Mimikry der Kuckuckseier. J. Orn. 72: 461-472.

Rothstein, S.I. 1975. An experimental and teleonomic investigation of avian brood parasitism. Condor 77: $250-271$.

Rothstein, S.I. 1982. Mechanisms of avian egg recognition: which egg parameters elicit responses by rejector species? Behav. Ecol. Sociobiol. 11: 229-239.

SWynnerton, C.F.M. 1918. Rejection by birds of eggs unlike their own; with remarks on some of the cuckoo problems. Ibis (10)6: 127-154.

Victoria, J.K. 1972. Clutch characteristics and egg discriminative ability of the African Village Weaverbird Ploceus cucullatus. Ibis 114: 367-376. 